\title{
Corrigendum
}

\section{GADD34 induces cell death through inactivation of Akt following traumatic brain injury}

\author{
JM Farook, J Shields, A Tawfik, S Markand, T Sen, SB Smith, D Brann, KM Dhandapani and N Sen
}

Cell Death and Disease (2013) 4, e813; doi:10.1038/cddis.2013.336; published online 26 September 2013

Correction to: Cell Death and Disease (2013) 4, e754; doi:10.1038/cddis.2013.280; published online 1 August 2013

Since the publication of this paper, the authors have noticed that there was an error in Figure 1c. The confocal image for $\mathrm{TBI}$ at $24 \mathrm{~h}$ was incorrect. The error has now been rectified. The corrected article appears online together with this corrigendum.

The authors would like to apologize for any inconvenience this may have caused. a
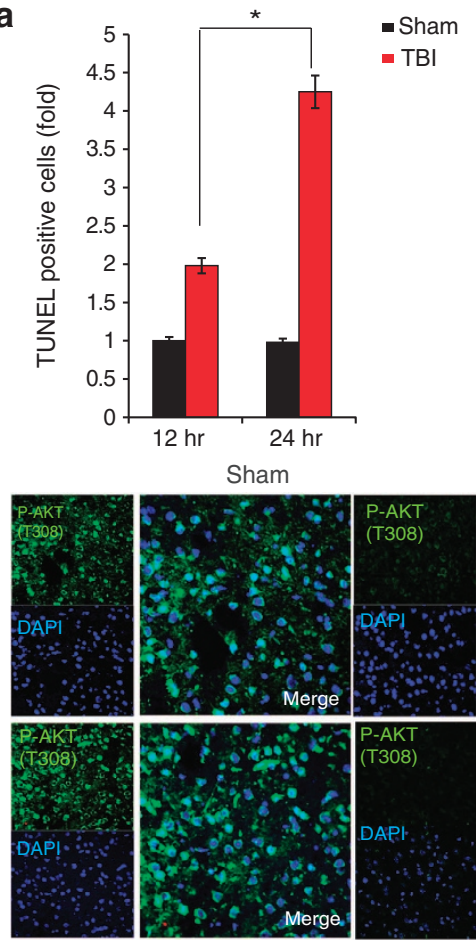

b

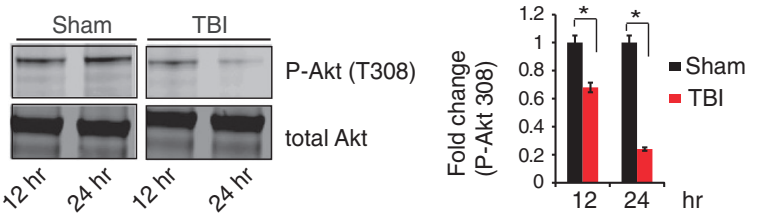

TBI

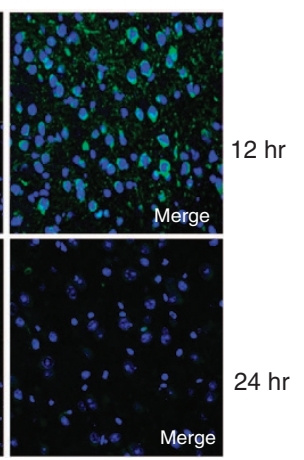

d

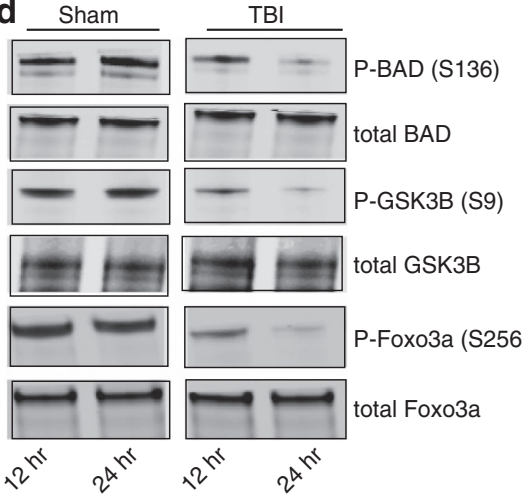

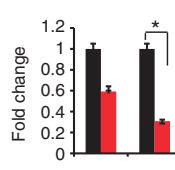
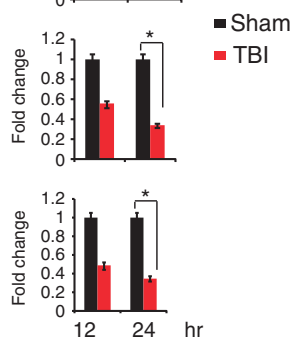

e
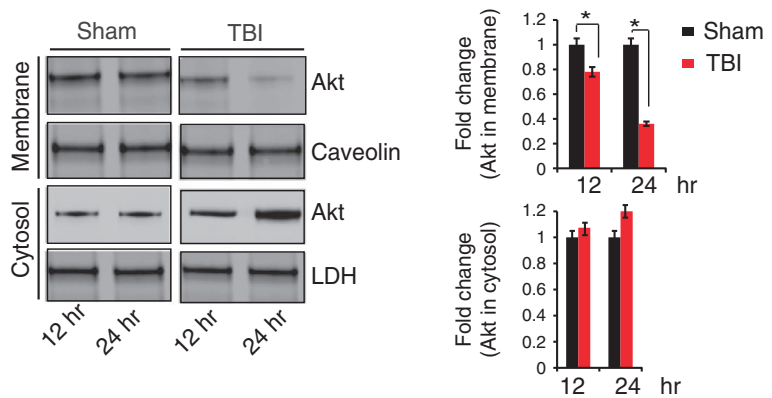

Figure 1 Inactivation of Akt is associated with cell death following TBI. (a) TUNEL staining was done to identify cell death at 12 and $24 \mathrm{~h}$ after TBI. Quantitative analysis shows that TUNEL staining was increased more than twofold after $24 \mathrm{~h}$ post TBI in the pericontusional cortex. (b and c) Phosphorylation of Akt (T308) was determined by western blot and immunofluorescent microscopy. Changes in phosphorylation status of Akt (P-Akt T308) was measured quantitatively. (d) Phosphorylation of downstream proteins of Akt, such as GSK3B, Fox03a and BAD was determined by western blot analysis 12 and $24 \mathrm{~h}$ post TBI. (e) Membrane and cytosolic fraction of Akt was determined in the cortex at 12 and $24 \mathrm{~h}$ post Sham or TBI in mice. Level of both cytosolic and membrane Akt was determined at 12 and $24 \mathrm{~h}$ post TBI quantitatively. ${ }^{*} P<0.01, n=3$, one-way ANOVA, mean \pm S.E.M. 